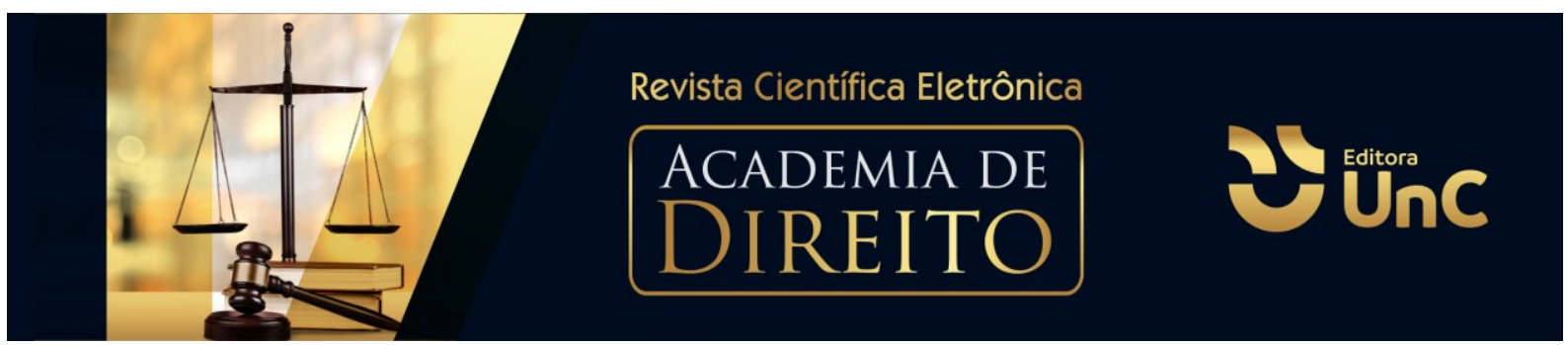

\title{
O INSTITUTO DA ESTABILIDADE DO SERVIDOR PÚBLICO EFETIVO COMO INSTRUMENTO PARA A QUALIDADE, CONTINUIDADE E EFETIVIDADE DO SERVIÇO PÚBLICO
}

\section{THE STABILITY INSTITUTE OF THE PERMANENT PUBLIC SERVANT AS AN INSTRUMENT FOR QUALITY, CONTINUITY AND EFFECTIVENESS OF PUBLIC SERVICE}

\author{
Silmar Ferreira ${ }^{1}$ \\ Willian Vailate ${ }^{2}$
}

\begin{abstract}
RESUMO
A estabilidade consiste em uma garantia constitucional concedida aos servidores públicos efetivos, após o preenchimento de certas condições ou do advento de termo, cuja finalidade é impedir o desligamento do servidor sem a observância de certos requisitos estabelecidos pela própria Constituição. Atualmente, muito tem se discutido a respeito da necessidade de uma reforma administrativa sob a justificativa de que os servidores públicos consomem uma grande parte das receitas públicas sem dar a devida contrapartida, bem como que as garantias dadas a esses servidores freiam o Estado e inviabilizam a gestão. O presente artigo tem como objetivo analisar o impacto do instituto da estabilidade do servidor público efetivo na prestação de serviços públicos, identificando se ele tem um reflexo positivo ou negativo na qualidade, continuidade e efetividade do serviço público. Através de pesquisa bibliográfica, embasada no método dedutivo, constatou-se que a estabilidade, além de uma garantia do servidor, é uma garantia para a coletividade. Seu fundamento encontra-se na continuidade administrativa bem como na independência funcional do servidor, para que este tenha segurança em realizar seu trabalho sem sucumbir a pressões externas, garantindo-se, assim, que o interesse público seja atendido. Assim, pode-se concluir que, a existência de regramentos para a prestação dos serviços, bem como de garantias para os responsáveis por prestá-los é essencial para o bom funcionamento da máquina pública.
\end{abstract}

Palavras-chave: Administração Pública. Eficiência. Estabilidade. Serviço público. Servidor público.

${ }^{1}$ Graduando em Direito, Universidade do Contestado. Campus Canoinhas. Santa Catarina. Brasil. E-mail: ferreira.silmar@outlook.com

${ }^{2}$ Especialista Lato Sensu em Direito Civil e Direito Processual Civil pela Faculdade Verbo Educacional. Especialista Lato Sensu em Direito Constitucional pela Universidade Estácio de Sá. Bacharel em Direito pela Universidade do Contestado (UnC). Advogado inscrito nos quadros da Ordem dos Advogados do Brasil do Estado de Santa Catarina. Membro efetivo da Comissão OAB Vai à Escola da Ordem dos Advogados do Brasil (OAB), Subseção de Canoinhas/SC (triênio 2019/2021). Professor de Graduação em Direito da Universidade do Contestado (UnC). Santa Catarina Brasil. E-mail: willianvailate@gmail.com 


\begin{abstract}
Stability means a constitutionals guarantee granted to permanent civil servants, following the fulfilment of certain conditions or tenure of employment, whose purpose is to prevent the civil servant from being dismissed without observing certain requirements established by the Constitution itself. Currently, much is been discussed about the need for administrative reform under the justification that public servants utilise a large part of public funds without any tangible return, as well as that the guarantees given to these civil servants restrain the State and hinder staff management. This article aims to analyse the impact of stability of the permanent civil servant on the provision of public services, identifying whether it has a positive or negative impact on the quality, continuity and effectiveness of the public service. Through bibliographic research, based on deductive method, it was found that stability, in addition to a guarantee for the civil servant, is a guarantee for the community. Its foundation is in the continuation of administration as well as in the functional independence of the servant, so that they have security in carrying out their work without succumbing to external pressure, thus ensuring that the public interest is served. Therefore, it can be concluded that the existence of rules for the provision of services, as well as guarantees for those responsible for providing them, is essential for the proper functioning of the public system.
\end{abstract}

Keywords: Public Administration. Efficiency. Stability. Public service. Civil servant.

\title{
1 INTRODUÇÃO
}

O ordenamento jurídico garante direitos e impõe obrigações a todos, especialmente, ao Estado, que, na relação com seu povo, está subordinado a regras de direito, devendo buscar sempre o bem comum, através da garantia das liberdades individuais e dos direitos fundamentais, não podendo agir de forma arbitrária.

O Estado para assegurar que seus deveres para com o povo sejam atendidos utiliza-se de material humano, os chamados agentes públicos, que estão ligados ao Estado por uma relação jurídica, sendo que, é através desse material humano que ele se faz presente na vida da coletividade.

As relações jurídicas entre o Estado e os agentes públicos variam de acordo com as especificidades de cada categoria. Aqui, no entanto, será tratada, em especial, da relação entre o Estado e os servidores públicos titulares de cargo efetivo em regime estatutário, os quais possuem algumas garantias, entre elas, a estabilidade.

Ocorre que, muito tem se discutido a respeito desse instituto, sendo apontado por muitos como uma das causas da ineficiência da máquina administrativa. O senso comum, por vezes, coloca os servidores públicos como responsáveis pela má 
qualidade dos serviços públicos. Desta forma, para evitar uma visão rasa e equivocada sobre o assunto, é necessária uma análise mais crítica e racional acerca de tudo aquilo que diz respeito a esse instituto.

Diante disso, o presente artigo buscará responder ao seguinte problema: o instituto da estabilidade do servidor público efetivo contribui para a qualidade, continuidade e efetividade do serviço público?

Para tanto, através de pesquisa bibliográfica apoiada no método dedutivo, inicialmente, se buscará entender um pouco da estrutura administrativa, discorrendose sobre a Administração Pública e seus princípios, o serviço público e os agentes públicos. Na sequência, realizar-se-á uma análise da eficiência administrativa e um exame sobre o instituto da estabilidade, diferenciando-o da efetividade e vitaliciedade, verificando, por fim, quais suas consequências para o serviço público e para a eficiência administrativa.

\section{ORGANIZAÇÃO E PRINCÍPIOS DA ADMINISTRAÇÃO PÚBLICA}

\subsection{ADMINISTRAÇÃO PÚBLICA}

Inicialmente, é importante destacar que a Administração não se confunde com Governo. Este se manifesta através da atividade política discricionária, aquela pratica atividade neutra, que, em regra, é vinculada à lei ou norma técnica, os chamados atos de execução. Pode-se dizer que a Administração é o instrumento utilizado pelo Estado para a prática das opções políticas realizadas pelo Governo (MEIRELLES, 2016).

Conceituar Administração Pública não se mostra das tarefas mais fáceis, como ensina Matias Pereira (2018, p. 74) "a ausência de uma definição clara e consciente do termo Administração Pública decorre da diversidade de sentido da própria expressão". Di Pietro (2019) distingue Administração Pública em sentido objetivo e sentido subjetivo.

Em sentido objetivo, grafada com iniciais minúsculas, administração pública é definida como a função administrativa, abarcando as atividades desenvolvidas pelas entidades administrativas do Estado (DI PIETRO, 2019). 
Trata-se da própria gestão dos interesses públicos executada pelo Estado, seja através da prestação de serviços públicos, seja por sua organização interna, ou ainda pela intervenção no campo privado, algumas vezes até de forma restritiva (poder de polícia) (CARVALHO FILHO, 2018, p. 11).

A atividade administrativa é desenvolvida tipicamente pelo Poder Executivo. Isso, porém, não impede que os Poderes Legislativo e Judiciário, que tipicamente e respectivamente, possuem função legislativa e judiciária, exerçam função administrativa de forma atípica. Isso ocorre, por exemplo, quando praticam atos de gestão de seu quadro de colaboradores (NOHARA, 2019).

Em sentido subjetivo, com iniciais maiúsculas, a Administração Pública corresponde a todo o aparelhamento do Estado voltado à realização de serviços públicos (MEIRELLES, 2016). Di Pietro (2019, p. 80) ensina que se considera "agora os sujeitos que exercem a atividade administrativa, a Administração Pública abrange todos os entes aos quais a lei atribui o exercício dessa função". Sintetizando, corresponde aos órgãos, entidades e os agentes responsáveis pela atividade administrativa.

Medauar (2018) leciona que a Administração Pública é dividida vertical e horizontalmente. Verticalmente, essa divisão se dá na distribuição de competências realizada pela Constituição entre os entes da federação, quais sejam, a União, os Estados, o Distrito Federal e os Municípios, pessoas jurídicas de direito público interno. Horizontalmente, ocorre com a classificação entre Administração Direta e Administração Indireta.

AAdministração Pública Direta, também chamada de centralizada, é composta pelas pessoas jurídicas de direito público interno - União, Estados, Distrito Federal e Municípios. Além da capacidade administrativa, possuem capacidade política (ALMEIDA, 2019). Segundo Carvalho Filho (2018), são ao mesmo tempo titulares e executoras dos serviços por ela prestados.

Logicamente, essas pessoas, por si só, não conseguiriam, concentradamente, atender todas as suas obrigações. Por isso, podem, por meio do processo de desconcentração administrativa, criar órgãos responsáveis por atividades específicas. Este processo é conceituado por Di Pietro (2019) como uma distribuição de competências dentro de uma mesma pessoa jurídica, sendo que, essa distribuição está ligada à hierarquia. O órgão, cabe salientar, não constitui pessoa jurídica distinta 
da que a criou, não possui capacidade jurídica própria (CARVALHO FILHO, 2018). Esse processo, como explica Mello (2014), também pode ser utilizado pela Administração Pública Indireta.

A Administração Pública Indireta é composta por entidades que são resultado da descentralização administrativa. O Estado não exerce diretamente (centralizadamente) suas atividades, mas transfere-as a pessoas jurídicas que são especificamente criadas para esse fim, que podem ter personalidade jurídica de direito público ou privado, as quais possuem poderes específicos e estão sujeitas ao controle finalístico (tutela administrativa) pela entidade da Administração Direita que a criou. É importante destacar que a despeito da tutela, não há hierarquia entre entidade da Administração Direta e Indireta. Integram a Administração Pública Indireta as autarquias, as fundações públicas, as sociedades de economia mista e as empresas públicas (MEDAUAR, 2018).

\subsection{PRINCÍPIOS CONSTITUCIONAIS DO DIREITO ADMINISTRATIVO}

Oliveira (2013, p. 27) diz que "os princípios são os pilares que sustentam todo - Direito Administrativo, garantindo sua unidade e autonomia científica". A Constituição de 1988 inovou ao fazer menção expressa de alguns princípios que regem tanto a Administração Pública direta quanto a indireta. São os chamados princípios expressos e estão previstos no caput do art. 37 da Constituição Federal, são eles o da legalidade, impessoalidade, moralidade, publicidade e eficiência (DI PIETRO, 2019).

Além dos princípios expressos, conforme leciona Mello (2014), existem os chamados princípios implícitos, esses decorrem dos expressos ou são implicações do próprio Estado de Direito e do sistema constitucional. A doutrina enumera vários princípios implícitos, no entanto, aqui serão discorridos sobre aqueles dois que, segundo Mello (2014), delineiam a disciplina normativa do Direito Administrativo, são eles: o princípio da supremacia do interesse público sobre o privado e o princípio da indisponibilidade, pela Administração, do interesse público.

Mello (2014) conceitua interesse público como aquele resultante de um conjunto de interesses que os indivíduos possuem quando considerados como 
membros da coletividade. Como percebe-se, os indivíduos não podem ser observados isoladamente, mas sim como integrantes do grupo.

Marinela (2018, p. 74 ) explica que o princípio da supremacia do interesse público sobre o privado "determina privilégios jurídicos e um patamar de superioridade do interesse público sobre o particular". Carvalho Filho (2018) destaca que a Administração deve deixar de lado o individualismo, caracterizando-se como "Estado de bem estar", zelando pelo interesse público. Esse princípio se encontra presente, por exemplo, na desapropriação, visto que o interesse público sobre determinado bem tem prevalência ao interesse do proprietário.

O princípio da indisponibilidade do interesse público dita que o Estado é apenas gestor do interesse público e não proprietário, não podendo dele dispor da maneira que Ihe aprouver. A Administração Pública tem o poder/dever de zelar e resguardar o interesse da coletividade que representa (MELLO, 2014).

O princípio da legalidade refere-se à atuação administrativa, que deve sempre decorrer da lei. A Administração Pública deve sempre estar adstrita à lei (DI PIETRO, 2019). Segundo Meirelles (2016), a Administração Pública somente pode fazer aquilo que a lei autoriza, diferindo do particular que pode fazer tudo aquilo que a lei não proíbe. Disso percebe-se que, quando aplicado à Administração, o princípio da legalidade é mais restrito que aquele previsto no art. $5^{\circ}$, II, da Constituição.

Por sua vez, o princípio da impessoalidade possui duas facetas. A primeira delas está no sentido de que a Administração deve sempre atender ao fim imposto pela norma de forma impessoal, sem diferenciar seus destinatários. A segunda está no fato de que se deve, sempre, excluir a promoção pessoal de autoridades e servidores públicos das ações realizadas pela a Administração Pública (MEIRELLES, 2016).

Oliveira (2013) ensina que no sentido da igualdade ou isonomia, o princípio da impessoalidade obriga a Administração Pública a dispensar tratamento impessoal e isonômico aos particulares, sendo vedada a discriminação odiosa ou desproporcional. O autor ainda lembra que a igualdade a ser buscada é a material, não a formal. Assim, deve ser sempre analisada à luz da proporcionalidade, onde aqueles em situação de igualdade devem ter tratamento igualitário, porém, aqueles que se encontrem em situação de desigualdade devem receber tratamento diferenciado. 
O princípio da moralidade, conforme ensina Oliveira (2013), mostra-se de difícil conceituação, visto que há complexidade em descrever o que é moralmente legítimo. Marinela (2018, p. 85) dispõe que "esse princípio se relaciona com a ideia de honestidade, exigindo a estrita observância de padrões éticos, de boa-fé, de lealdade". Segundo a autora a moralidade administrativa não se confunde com a moralidade comum, esta preocupar-se-ia com a distinções entre o bem e o mal, aquela, por sua vez, seria composta não somente por correção de atitudes, mas também por regras de boa administração, que se ligaria ao interesse do povo e ao bem comum.

Moraes (2019) explica que o princípio da publicidade exige que sejam divulgados os atos da Administração para conhecimento do público em geral e, consequentemente, o início da produção de seus efeitos. Ainda, destaca sua importância pelo fato que "somente a publicidade evita os dissabores existentes em processos arbitrariamente sigilosos, permitindo-se os competentes recursos administrativos e as ações judiciais próprias" (MORAES, 2019, p. 368).

A eficiência ganhou status de princípio expresso da Administração Pública com a Emenda Constitucional no 19 de 1998. Como bem destaca Moraes (2019), essa mudança no dispositivo constitucional serviu para findar com uma discussão doutrinaria e jurisprudencial sobre sua existência como princípio implícito.

Sobre o princípio da eficiência é oportuno apresentar a definição de Marinela (2018, p. 90):

\begin{abstract}
A eficiência exige que a atividade administrativa seja exercida com presteza, perfeição e rendimento funcional. Consiste na busca de resultados práticos de produtividade, de economicidade, com a consequente redução de desperdícios do dinheiro público e rendimentos típicos da iniciativa privada, sendo que, nessa situação, o lucro é do povo; quem ganha é o bem comum.
\end{abstract}

Di Pietro (2019) apresenta o referido princípio em dois aspectos. No primeiro, é relacionado a atuação do agente público, devendo esse apresentar um bom desempenho para atingimento de melhores resultados. No segundo, está relacionado a maneira de organizar a Administração Pública, para atender esse princípio, a estrutura e disciplina administrativa devem ser voltadas também para a busca dos melhores resultados.

A doutrina costuma pregar cautela quanto a aplicação deste princípio. Mello (2014, p. 126) cita que "tal princípio não pode ser concebido senão na intimidade do 
princípio da legalidade, pois jamais uma suposta busca de eficiência justificaria postergação daquele que é o dever administrativo por excelência". Dos ensinamentos do eminente autor conclui-se que, apesar de ser um princípio importante para a atuação administrativa, não pode ser justificativa para atuações arbitrarias.

\title{
3 DOS SERVIÇOS E AGENTES PÚBLICOS
}

\subsection{DO SERVIÇO PÚBLICO}

A Constituição dispõe em seu art. 175 que "incumbe ao Poder Público, na forma da lei, diretamente ou sob o regime de concessão ou permissão, sempre através de licitação, a prestação de serviços públicos" (BRASIL, 1988). Do dispositivo constitucional denota-se o papel essencial da Administração Pública na prestação dos serviços públicos. Nesse sentido, aponta Meirelles (2016, p. 417) que "a atribuição primordial da Administração Pública é oferecer utilidades aos administrados, não se justificando sua presença senão para prestar serviços à coletividade". Mello (2014), destaca que no serviço público a figura central não é seu titular ou prestador, mas sim o usuário.

Segundo Mello (2014, p. 695):

\begin{abstract}
Serviço público é toda atividade de oferecimento de utilidade ou comodidade material destinada à satisfação da coletividade em geral, mas fruível singularmente pelos administrados, que o Estado assume como pertinente a seus deveres e presta por si mesmo ou por quem lhe faça as vezes, sob regime de Direito Público - portanto consagrador de prerrogativas de supremacia e restrições especiais -, instituído em favor dos interesses definidos como públicos no sistema normativo.
\end{abstract}

Marinela (2018) classifica o serviço público em próprio e impróprio, essa classificação se dá conforme a essencialidade e a possibilidade de delegação. Podem também serem chamados de serviços públicos propriamente ditos (próprios) e serviços de utilidades pública (impróprios). Os serviços próprios seriam aqueles que estão intimamente relacionados com o Poder Público, são essenciais e indispensáveis a continuidade da sociedade e do próprio Estado. Os impróprios, por sua vez, são aqueles que não seriam essenciais a mantença da sociedade, mas que, entretanto, são convenientes à vida em sociedade e ao Estado. 
Os serviços próprios, em regra, não são passiveis de delegação, o que, no entanto, pode ser excetuado caso haja previsão legal para tanto. São prestados diretamente pela Administração, com o uso de sua supremacia, exemplo são os serviços de segurança, higiene e saúde pública. Os impróprios a Administração presta, de forma remunerada, por meio da Administração Indireta ou, ainda, de forma delegada a concessionário, permissionário e autorizatários (MEIRELLES, 2016).

O serviço púbico de qualidade deve ser prestado com excelência, com um grau positivo de relevância, que propicie satisfação aos destinatários. O dicionário Michaelis (2020) define qualidade como "traço positivo inerente que faz alguém ou algo se sobressair em relação aos demais; excelência, talento, virtude".

Como bem destaca Carvalho Filho (2018, p. 11):

Seja qual for a hipótese da administração da coisa pública (res publica), é inafastável a conclusão de que a destinatária última dessa gestão há de ser a própria sociedade, ainda que a atividade beneficie, de forma imediata, o Estado. É que não se pode conceber o destino da função pública que não seja voltado aos indivíduos, com vista a sua proteção, segurança e bemestar.

Outrossim, além de eficiente, o serviço público deve ser efetivo, termos que não se confundem. Como já visto, a eficiência exige que a atividade do agente público seja prestada de forma que melhor seja seu desempenho e resultados. A efetividade, porém, conforme ensina Carvalho Filho (2018), se dirige aos resultados que as ações administrativas alcançam, ao atingimento dos objetivos. Deste modo, uma ação pode ser eficiente, mas não efetiva, isto é, sem atingir os seus objetivos.

\subsubsection{Princípios do Serviço Público}

Além dos princípios gerais do Direito Administrativo, ao serviço público se aplicam alguns princípios próprios. Meirelles (2016) elenca cinco princípios específicos do serviço público, quais sejam, o da permanência ou continuidade, o da generalidade, o da eficiência, o da modicidade e o da cortesia.

O princípio da generalidade, como ensina Carvalho Filho (2018), possui dois aspectos. De um lado, orienta que os serviços públicos devem ser prestados da forma mais ampla possível, ou seja, beneficiando o maior número de pessoas cabíveis, além 
disso, devem abarcar a maior área territorial possível. Outrossim, esse princípio em muito se liga ao princípio da impessoalidade expresso no art. 37 da Constituição, pois o serviço público deve ser prestado sem que haja discriminação entre os usuários.

O princípio da eficiência do serviço público seria uma ratificação do princípio da eficiência da Administração Pública, já anteriormente abordado. No entanto, com os ensinamentos de Meirelles (2016), conclui-se que quando aplicado especificamente ao serviço público, o principio citado vai além, visto que exige sua atualização.

Alguns autores, como Oliveira (2019), enumeram como princípio específico do serviço público o da atualidade, deixando de lado, aqui, o da eficiência. O princípio da atualidade exige que a Administração Pública leve "em consideração o fato de que os serviços públicos devem se adaptar à evolução social e tecnológica" (OLIVEIRA, 2019 , p. 257). Desta forma, o serviço público deve acompanhar as evoluções da sociedade, mantendo-se sempre atualizado para melhor atender a coletividade.

Já o princípio da cortesia liga-se ao bom tratamento desprendido ao usuário. Segundo Gasparini (2012, p. 358-359), "exige-se de quem presta serviço público um tratamento urbano, sem o desdém daquele que o oferece". O autor ainda continua destacando que "a prestação, em tais condições, não é um favor do agente ou da Administração Pública, mas dever de um e de outro e, sobretudo, um direito do cidadão".

O princípio da modicidade, por sua vez, exige que o serviço público, quando prestado mediante remuneração do usuário, não seja excessivamente oneroso. Isto porque se tal serviço é prestado em favor da coletividade, não pode ela sofrer uma forte carga financeira para utilizá-lo (MELLO, 2014).

\subsubsection{Da Continuidade do Serviço Público}

Princípio específico do serviço público, é também, por alguns administrativistas, chamado de princípio da permanência (COUTO, 2019). Para um entendimento inicial do aludido princípio, convém transcrever os ensinamentos de Carvalho Filho (2018, p. 347):

Esse princípio indica que os serviços públicos não devem sofrer interrupção, ou seja, sua prestação deve ser contínua para evitar que a paralização provoque, como às vezes ocorre, colapso nas múltiplas atividades 
particulares. A continuidade deve estimular o Estado ao aperfeiçoamento e à extensão do serviço, recorrendo, quando necessário, às modernas tecnologias, adequadas à adaptação da atividade às novas exigências sociais.

Da continuidade do serviço público existem algumas decorrências importantes para o Direito Administrativo. Marinela (2018) elenca alguns instrumentos que visam garanti-la, destacando o direito de greve dos servidores públicos, que, apesar de não estar regulamentado, deve seguir as diretrizes da lei n 7.783 de 1989 (dispõe sobre o exercício do direito de greve na iniciativa privada), onde são fixados os limites desse direito, de modo garantir a continuidade do serviço. Do mesmo modo, no que concerne ao servidor, destaca a suplência, delegação, substituição e remoção, instrumentos que garantem a prestação das atividades administrativas quando as funções públicas estiverem temporariamente vagas.

Outra importante prerrogativa da Administração Pública para a continuidade do serviço público diz respeito aos contratos administrativos. Segundo o art. 78, XV, da lei $n^{\circ} 8.666$ de 1993, em caso de inadimplemento por parte da Administração, o contratado deve, ainda assim, continuar prestando o serviço pelo prazo de noventa dias. Por fim, Marinela (2018) lembra dos instrumentos postos à Administração para que, nos casos de delegação do serviço público, possa garantir sua continuidade, como a ocupação provisória, reversão e a encampação.

Importante destacar que quando o serviço for prestado em regime de concessão ou permissão, a lei n ${ }^{\circ} 8.987$ de 1995 , em seu art. $6^{\circ}, \S 3^{\circ}$, traz hipótese de interrupção do serviço sem que caracterize descontinuidade. Assim, não descaracteriza a continuidade quando o serviço for interrompido por motivo de ordem técnica ou de segurança das instalações, bem como por inadimplemento do usuário, considerando o interesse da coletividade. Deve-se destacar, contudo, que essa interrupção somente pode se dar em situações de emergência ou após aviso prévio ao usuário (BRASIL, 1995).

\subsection{DOS AGENTES PÚBLICOS}

Carvalho Filho (2018) leciona que agentes públicos, em sentido amplo, são todos aqueles que, a qualquer título, possuem o exercício de uma função pública como 
representantes do Estado. Essa função pode ser gratuita ou remunerada, política ou jurídica, definitiva ou transitória. Para o referido doutrinador "o Estado só se faz presente através das pessoas físicas que em seu nome manifestam determinada vontade, e é por isso que essa manifestação volitiva acaba por ser imputada ao próprio Estado" (CARVALHO FILHO, 2018, p. 631).

Di Pietro (2019), por sua vez, classifica os agentes públicos em agentes políticos, servidores públicos, militares e particulares em colaboração com o Poder Público.

Os agentes políticos, como ensina Gasparini (2012), se ligam à Administração Pública numa relação política. Esclarecedora é a conceituação trazida por Mello (2014, p. 253-254):

Agentes políticos são os titulares de cargos estruturais à organização política do país, ou seja, ocupantes dos que integram o arcabouço constitucional do Estado, o esquema fundamental do Poder. Daí que se constituem nos formadores da vontade superior do Estado. São agentes políticos apenas o Presidente da República, os Governadores, Prefeitos e respectivos vices, os auxiliares imediatos dos Chefes do Executivo, isto é, Ministros e Secretários das diversas Pastas, bem como os Senadores, Deputados federais e estaduais e os Vereadores.

Di Pietro (2019) completa que os agentes políticos exercem atividades de direção e colegislativas, as quais importam em fixação de metas, diretrizes e planos de governo. São, em regra, investidos por eleição, no entanto, alguns deles, podem decorrer de nomeação.

Já os terceiros em colaboração, conforme exemplifica Di Pietro (2019), são aquelas pessoas físicas que, sem vínculo empregatício, prestam algum tipo de serviço ao Estado, com ou sem remuneração. Isso pode ocorrer sob diversos títulos.

Fazem parte dessa classe os chamados agentes honoríficos, que:

São cidadãos convocados, designados ou nomeados para prestar, transitoriamente, determinados serviços ao Estado, em razão de sua condição cívica, de sua honorabilidade ou de sua notória capacidade profissional, mas sem qualquer vínculo empregatício ou estatutário e, normalmente, sem remuneração (MEIRELLES, 2016, p. 84). 
Meirelles (2016) completa, ainda, que apesar de exercerem função pública, não são servidores públicos e não há vínculo empregatício, somente são equiparados a funcionário público para fins penais. É o exemplo do mesário e do jurado.

Quanto aos militares, a doutrina não é una em relação a sua classificação como categoria própria de agentes públicos. Alguns, como Marinela (2018), os enquadra como fazendo parte dos servidores públicos, distinguindo-se em civis e militares. No entanto, Di Pietro (2019) aponta que, após a Emenda Constitucional nº 19 de 1998, excluiu-se em relação a eles o termo "servidor", deste modo, a autora propugna pela inclusão desses como uma categoria própria dos agentes públicos. Segundo a autora, essa classe abrange:

As pessoas físicas que prestam serviços às Forças Armadas - Marinha, Exército e Aeronáutica (art. 142, caput, e $\S 3^{\circ}$, da Constituição) - e às Polícias Militares e Corpo de Bombeiros Militares do Estados, Distrito Federal e dos Territórios (art. 42), com vínculo estatutário sujeito a regime jurídico próprio, mediante remuneração paga pelos cofres públicos (DI PIETRO, 2019, p. 686).

No que se refere aos militares é ainda importante destacar que são organizados com base na hierarquia e disciplina. Ainda, Ihes é vedado o exercício do direito de greve e de sindicalização, bem como, enquanto em atividade, não podem filiar-se a partidos políticos (COUTO, 2019).

\subsubsection{Servidores Públicos}

Seguindo a classificação de Di Pietro (2019), a última categoria dos agentes públicos é a dos servidores públicos. Esta, por sua vez, subdivide-se em outras três subcategorias, quais sejam, os servidores estatutários, os empregados públicos e os servidores temporários.

Marinela (2018, p. 695-696), sobre o empregado público, assim leciona:

O regime de emprego, independentemente de estar nas pessoas jurídicas de direito público ou privado e em qualquer ordem política, federal, estadual ou distrital, submete-se ao princípio da unicidade normativa, porque o conjunto das normas reguladoras está previsto em um único diploma legal, a Consolidação da Leis do Trabalho (CLT). Assim, a relação tem natureza contratual, o regime é o trabalhista (celetista) e submete-se às regras do art. $7^{\circ}$ da CF. 
Destaca-se que o ponto crucial que diferencia o empregado público do servidor estatutário é a forma que ele se liga à Administração. Enquanto o primeiro se liga por uma relação contratual de caráter trabalhista, o segundo relaciona-se com o Estado por uma relação jurídica embasada em estatuto próprio (CARVALHO FILHO, 2018).

Nohara (2019) ensina que os servidores temporários são aqueles previstos no art. 37, IX, da Constituição, e exercem uma função de regime jurídico especial que deve ser regulado por cada unidade da federação, não podendo, porém, se vincularem definitivamente à Administração. Para entender as possibilidades de sua contratação é imperioso transcrever o dispositivo citado, o qual diz que "a lei estabelecerá os casos de contratação por tempo determinado para atender à necessidade temporária de excepcional interesse público" (BRASIL, 1988).

Os servidores públicos estatutários, por sua vez, são assim chamados porque:

\begin{abstract}
Submetem-se ao regime estatutário, estabelecido em lei por cada uma das unidades da federação e modificável unilateralmente, desde que respeitados os direitos já adquiridos pelo servidor. Quando nomeados, eles ingressam numa situação jurídica previamente definida, à qual se submetem com o ato da posse; não há possibilidade de qualquer modificação das normas vigentes por meio de contrato, ainda que com a concordância da Administração e do servidor, porque se trata de normas de ordem pública, cogentes, não derrogáveis pelas partes (DI PIETRO, 2019, p. 638).
\end{abstract}

Meirelles (2016) também os chama de servidores públicos em sentido estrito, destacando que se tratam de titulares de cargo público efetivo e em comissão que integram a Administração Pública Direita e as pessoas jurídicas de direito público integrantes da Administração Indireta. Mello (2014) discorre que, integram, também, o Poder Judiciário e o Poder Legislativo.

Carvalho Filho (2018) leciona que os cargos em comissão são de ocupação transitória. Aqueles que os ocupam são nomeados com base na relação de confiança existente entre o agente e a autoridade que o nomeou. Por esse motivo, são também chamados de cargos de confiança. São caracterizados pelo art. 37, II, da Constituição como de livre nomeação e exoneração. Por sua natureza, esses cargos não permitem que seus titulares adquiram estabilidade. Outrossim, não é necessário a prestação de concurso público para o ingresso, bem como a exoneração independe de formalidades, sendo esta de exclusivo critério da autoridade nomeante. Meirelles 
(2016) lembra ainda que conforme preceitua o art. 37, V, da Constituição, esses cargos se destinam somente às atribuições de direção, chefia e assessoramento.

Os servidores públicos estatutários titulares de cargo efetivo contam com mais garantias que a classe dos servidores analisada anteriormente. Para o ingresso é necessária a aprovação em concurso público, a nomeação possui caráter definitivo e, desde que atendidos determinados requisitos, adquirem estabilidade. Ainda, a retirada do quadro funcional desse servidor, necessita ser motivada e precedida de processo administrativo (MARINELA, 2018). Carvalho Filho (2018) discorre que constituem a maioria absoluta dos cargos que integram os quadros funcionais da Administração Pública.

Há, ainda, os cargos vitalícios, esses oferecem maior segurança que os cargos efetivos. Seus ocupantes somente o perderão em razão de sentença judicial transitada em julgado. Atualmente, são vitalícios os cargos para membros da Magistratura, Ministério Público e Tribunal de Contas (NOHARA, 2019).

\section{A ESTABILIDADE DO SERVIDOR PÚBLICO EFETIVO E SUAS CONSEQUÊNCIAS}

\subsection{A ESTABILIDADE}

Marinela (2018, p. 766) explica que a estabilidade:

[...] consiste em uma garantia constitucional de permanência no serviço público, e não no cargo, vinculado a atividade de mesma natureza de quando ingressou, assegurada ao servidor público, que tenha cumprido o período de prova, após ser submetido à avaliação especial de desempenho por comissão constituída para essa finalidade. Adquirida a vantagem, pode ser desinvestido por meio de processo administrativo com contraditório e ampla defesa, por processo judicial transitado em julgado e avaliação periódica.

Atualmente a estabilidade está prevista no art. 41 da Constituição, o qual dita serem estáveis "após três anos de efetivo exercício os servidores nomeados para cargo de provimento efetivo em virtude de concurso público" (BRASIL, 1988).

A estabilidade somente abrange os servidores públicos estatutários investidos em cargo de caráter efetivo. Somente pode ser nomeado para cargo em caráter efetivo aquele aprovado em concurso público. O direito não se estende aos titulares de cargo 
em comissão, nem àqueles que se ligam à Administração Pública em regime trabalhista (empregados públicos). Por sua vez, os ocupantes de cargos vitalícios, adquirem a chamada vitaliciedade (CARVALHO FILHO, 2018).

Outro requisito previsto pelo texto constitucional para a concessão da estabilidade é o efetivo exercício do cargo por três anos. A redação original do art. 41 da Constituição exigia dois anos de efetivo exercício, porém, após a Emenda Constitucional no 19 de 1998, passou-se a exigir-se três anos. Meirelles (2016) leciona que esse período é o chamado estágio probatório. No entanto, conforme lembra Marinela (2018), definir se o estágio probatório se confunde com as condições de estabilidade tem sido tema de bastante debate na doutrina e jurisprudência.

Ademais, insta salientar que nesse interstício de tempo entre a nomeação e a estabilidade, o servidor não fica desamparado de despedida arbitrária. Em qualquer hipótese que, nesse período, possa levar a perda do cargo, deve ser garantido ao servidor o direito à ampla defesa e ao contraditório, conforme dita a súmula $\mathrm{n}^{\circ} 21$ do Supremo Tribunal Federal (1963).

O último requisito para a conquista da estabilidade, como ensina Mello (2014), é a aprovação em avaliação de desempenho por comissão instituída para essa finalidade, cuja previsão consta no art. $41, \S 4^{\circ}$, da Constituição. Esse requisito foi uma novidade implantada pela Emenda Constitucional no 19 de 1998, em decorrência do princípio da eficiência.

O servidor, contudo, não pode sofrer com a omissão da Administração em constituir as referidas comissões e realizar as competentes avaliações.

\footnotetext{
Fatalmente haverá caso envolvendo o decurso do prazo de três anos sem que essa avaliação especial tenha sido feita nos moldes determinados pelo dispositivo constitucional. Como esse dever cabe à Administração Pública, o servidor não poderá ser prejudicado e adquirirá a estabilidade caso preencha as demais condições, apurando-se e responsabilizando-se o servidor que tinha o dever funcional de instituir a comissão especial ou a da própria comissão que, embora instituída, não exerceu sua atribuição (MELLO, 2014, p. 556)
}

Todavia, se os procedimentos forem corretamente adotados pela Administração, e a comissão, ainda dentro do período trienal, propugnar pela reprovação do servidor, cabe à Administração editar o ato de exoneração. Isso porque, 
a avaliação constitui procedimento prévio, não tendo força jurídica para, por si só, afastar o servidor (CARVALHO FILHO, 2018).

Couto (2019) lembra, ainda, da regra contida no art. 19 do Atos das Disposições Constitucionais Transitórias, que assegurou a estabilidade aos servidores públicos civis da União, dos Estados, do Distrito Federal e do Municípios, da Administração Direita, autárquica e fundacional, que não houvessem sido nomeados em razão de concurso público, mas que tivessem, na data da promulgação da Constituição (05 de outubro de 1988), mais de cinco anos contínuos de exercício.

Nesse sentido, ensina Di Pietro (2019) que existem duas classes de servidores estáveis. A primeiro é composta por aqueles que realizaram o concurso, foram nomeados e cumpriram o período e requisitos exigidos. A segunda seria composta por aqueles que adquiriram estabilidade excepcional, independente da prestação de concurso, mas aos quais as várias Constituições, de algum modo, os concederam o direito.

Di Pietro (2019) aponta algumas decorrências importantes do instituto da estabilidade, dentre as quais estão a reintegração, a disponibilidade e o aproveitamento. Reintegração é o direito daquele que conseguiu, judicialmente, ter sua demissão invalidada de ser reintegrado e ressarcido das vantagens que the seriam devidas caso a demissão não ocorresse. Uma vez que o servidor é reintegrado ao cargo de origem seu eventual ocupante, se estável, será reconduzido ao seu cargo que anteriormente ocupava ou posto em disponibilidade. A disponibilidade, por seu turno, significa a garantia de inatividade remunerada em caso da extinção do cargo ou de declaração de sua desnecessidade. Por fim, o aproveitamento constitui o reingresso do servidor colocado em disponibilidade aos quadros da Administração, de modo que, o reingresso deve se dar em cargo de natureza e vencimentos compatíveis com aquele que anteriormente ocupava.

O art. $41, \S 1^{\circ}$ da Constituição traz as hipóteses de perda do cargo pelo servidor estável:

O servidor público estável só perderá o cargo: I - em virtude de sentença judicial transitada em julgado; II - mediante procedimento administrativo em que Ihe seja assegurada a ampla defesa; III - mediante procedimento de avaliação periódica de desempenho, na forma de lei complementar, assegurada ampla defesa (BRASIL, 1988). 
Oliveira (2019) destaca que essas hipóteses previstas pelo texto constitucional possuem caráter de penalidade, constituindo demissão do serviço público. Carvalho Filho (2018), elenca três requisitos que devem ser atendidos para que um servidor estável possa ser regularmente demitido, são eles: o cometimento de infração grave; apuração da infração em processo administrativo e a garantia do direito à ampla defesa.

A terceira hipótese, prevista, no art. $41, \S 1^{\circ}$, III, da Constituição, trata-se de novidade trazida pela Emenda Constitucional no 19 de 1998 e busca atender o princípio da eficiência. Oliveira (2019), todavia, destaca que se trata de norma de eficácia limitada, dependendo de lei complementar que a regulamente, o que ainda não aconteceu, obstando, assim, sua aplicação.

Resta, ainda, a possibilidade da perda da estabilidade prevista no art. 169, § $4^{\circ}$, da Constituição. Aqui, não se trata de demissão e sim de exoneração, visto que não possui caráter de penalidade. Esta, pode ocorrer quando a Administração Pública excede os limites de pessoal estabelecidos por lei. Nesses casos o Poder Público deve respeitar algumas regras. Excedido o limite de gastos, a primeira conduta a ser tomada é a redução de, pelo menos, vinte por cento dos gastos com cargos em comissão e funções de confiança, caso não seja tal medida suficiente, deverão ser exonerados os servidores não estáveis e, por fim, caso ainda não tenha sido atingida a meta, poderá o servidor estável ser exonerado. O servidor estável que for exonerado por esse mecanismo faz jus a uma indenização que corresponde a um mês de remuneração por ano de serviço (CARVALHO FILHO, 2018).

Almeida (2019), lembra que o limite de gastos com pessoal é definido pelo art. 19 da Lei Complementar n. 101 de 2000, segundo a qual a União não pode ultrapassar o limite de cinquenta por cento de sua receita líquida e os Estados e Municípios o limite de sessenta por cento de sua receita líquida.

Oportuno, também, discorrer sobre as diferenças entre a estabilidade, a efetividade e a vitaliciedade. A estabilidade, como visto acima, é prerrogativa do servidor estatutário em permanecer no serviço público. A efetividade, por sua vez, está ligada ao cargo, a situação jurídica que o liga a Administração, distinguindo-se, assim, do cargo em comissão. Se ocupante de cargo em caráter efetivo, possui efetividade; se ocupante de cargo em comissão, não (CARVALHO FILHO, 2018). A vitaliciedade, por seu turno, segundo os ensinamentos de Marinela (2018), é uma garantia que, 
atualmente, a Constituição garante aos membros da Magistratura, do Ministério Público e dos Tribunais de Contas, após dois anos de exercício. Os ocupantes desses cargos, após adquirida a vitaliciedade, só os perderão em virtude de sentença judicial transitada em julgado.

\title{
4.2 A ESTABILIDADE E A AUTONOMIA FUNCIONAL DO SERVIDOR PÚBLICO
}

A estabilidade constitui garantia para que o servidor consiga e exerça suas funções de forma imparcial, sem que fique preso a ingerências cometidas pelos administradores. Nesse sentido, leciona Araújo (2018, p. 367):

\begin{abstract}
O direito de permanência no serviço público sempre foi considerado como medida de proteção ao servidor para o desempenho imparcial e impessoal de seu cargo, apenas voltado para o interesse público de suas funções, para as quais foi admitido. Administradores incompetentes, que não conseguem ou não querem responsabilizar seus subordinados na forma da lei, mas desejam colocar outros em seu lugar, consideram esse direito à estabilidade um entrave ao serviço, propugnando a volta aos tristes tempos em que o servidor ficava à mercê política (para não dizer pior) dos governantes de plantão e seus apaniguados.
\end{abstract}

Em sua tese Souza (2002, p. 79), assim discorre:

O principal objetivo da estabilidade é garantir imunidade aos servidores em relação a perseguições políticas e demissões injustas. O servidor público precisa sentir-se seguro para poder ter como prioridade única prestar serviços à sociedade, e não a seus superiores hierárquicos, por pressão ou visando a obtenção de simpatias e privilégios.

Mello (2014) destaca que a proteção aos ocupantes de cargos público visa à impessoalidade, com prestação de serviços técnicos, em condições propícias e, submissos somente a diretrizes administrativistas, inspiradas unicamente no interesse público, constituindo uma garantia aos administrados.

Isso porque, sem essa segurança, os agentes administrativos ficariam à mercê de governantes transitórios que poderiam manejá-los em proveito pessoal ou partidário, sendo que, é essa a inclinação dos ocupantes de posições de direção no país. A estabilidade e outras garantias dos servidores públicos são "benefícios outorgados aos titulares de cargos, mas não para regalo destes e sim para propiciar, 
em favor do interesse público e dos administrados, uma atuação impessoal do Poder Público" (MELLO, 2014, p. 268).

Do exposto, conclui-se que, a estabilidade, além de ser uma garantia ao servidor, é uma garantia à coletividade, visto que, possibilita que o servidor preste um serviço impessoal, se contrapondo a ingerências de administradores mal intencionados, podendo, com segurança, a eles se opor, a fim de atender tão somente as disposições legais e diretrizes administrativas voltadas ao interesse público.

\title{
4.3 A ESTABILIDADE E A EFICIÊNCIA ADMINISTRATIVA
}

Como visto, o princípio da eficiência exige que a atividade administrativa seja exercida com presteza, perfeição e rendimento funcional. Moraes $(2019$, p. 371) explica que "o administrador público precisa ser eficiente, ou seja, deve ser aquele que produz o efeito desejado, que dá bom resultado, exercendo suas atividades sob o manto da igualdade de todos perante a lei, velando pela objetividade e imparcialidade".

Carvalho Filho (2018) leciona que o dever de eficiência impõe que a atividade administrativa deve buscar perfeição, celeridade, coordenação e técnica. Outrossim, os agentes ocupantes dos cargos devem ter qualificação compatível, razão pela qual, é necessário rigor em seu recrutamento.

Com relação ao funcionalismo, Meirelles (2016, p. 117) explica:

\begin{abstract}
A eficiência funcional é, pois, considerada em sentido amplo, abrangendo não só a produtividade do exercente do cargo ou função como a perfeição do trabalho e sua adequação técnica aos fins visados pela Administração, para o quê se avaliam os resultados, confrontam-se os desempenhos e se aperfeiçoa o pessoal através de seleção e treinamento. Assim, a verificação da eficiência atinge os aspectos quantitativo e qualitativo do serviço, para aquilatar do seu rendimento efetivo, do seu custo operacional e da sua real utilidade para os administrados e para a Administração. Tal controle desenvolve-se, portanto, na tríplice linha administrativa, econômica e técnica.
\end{abstract}

Meirelles (2016) lembra ainda que a técnica é fator que se vincula à prestação de serviços públicos especializados. Assim, não cabe discricionariedade ou opções burocráticas em setores que o rendimento e funcionalidade dependam de métodos científicos que possuam sua eficiência comprovada. O que pode a Administração é escolher entre técnicas, mas não sobrepor critério leigo à técnico. 
Nesse sentido, Oliveira (2013) destaca que é necessário assegurar a qualificação técnica dos agentes para bem exercerem suas funções e, também, realizar avalições periódicas de desempenho.

\begin{abstract}
Atualmente, a eficiência é um fator fundamental para o exercício da função pública e especialmente, para ingresso e permanência do servidor nos quadros da Administração. A aquisição da estabilidade por parte do servidor estatutário, ocupante de cargo efetivo, após três anos de efetivo exercício da função, depende, necessariamente, da avaliação especial de desempenho por comissão instituída para essa finalidade, na forma do art. $41, \S 4^{\circ}$, da CBRF. Por outro lado, o servidor estável poderá perder o cargo 'mediante procedimento de avaliação periódica de desempenho, na forma de lei complementar, assegurada a ampla defesa' (art. 41, III, da CBRF) (OLIVEIRA, 2013, p. 120-121).
\end{abstract}

Das lições do autor, extrai-se que a eficiência está diretamente ligada a estabilidade, principalmente após as mudanças trazidas pela Emenda Constitucional $n^{\circ}$ 19. A avaliação de desempenho por ela introduzida como requisito para aquisição da estabilidade vem a cooperar com a eficiência, pois, através dela, se estabelece se o servidor é qualificado para a função.

Coutinho (2003) também leciona nesse sentido, afirmando que as mudanças nos requisitos para a aquisição da estabilidade e nas hipóteses de perda da mesma, vieram a atender a eficiência.

Souza (2002) discorre que a estabilidade constitui um meio para garantir a continuidade administrativa, bem como para proteger a sociedade contra ingerências de administradores que, querendo tirar proveito próprio, distribuem cargos de forma imprudente. Desse modo, é ela um instituto que ajuda a promover a eficiência e racionalidade da Administração.

\title{
4.4 A ESTABILIDADE E SEUS IMPACTOS NO SERVIÇO PÚBLICO
}

Coutinho (2003) ensina que o instituto da estabilidade existe devido a duas razões. Inicialmente, como já salientado, constitui garantia do próprio servidor, que tem a finalidade de lhe dar maior segurança para o desempenho de suas atividades. Outra razão de ser da estabilidade encontra-se na coletividade, uma vez que, constitui elemento que concorre para que o serviço seja prestado com qualidade. 
O servidor público é, por vezes, julgado, pelo senso comum, como o responsável pelas deficiências do setor público, sendo a ele imputada a responsabilidade pelas mazelas que afligem a Administração Pública. Porém, é necessário ter cautela e uma visão crítica para não se cair em um falso "consenso" criado (SOUZA, 2002).

A estabilidade é apontada, muitas vezes, como fator que leva à ineficiência e má qualidade do serviço público. No entanto, o instituto é também uma garantia à sociedade, visto que busca a moralidade, impessoalidade, técnica e eficiência da Administração como um todo e, consequentemente, ao serviço público.

Em vista disso, assim leciona Coutinho (2003, p. 85-86):

\begin{abstract}
Portanto, o fundamento da estabilidade do servidor encontra sua justificativa de existência, em última análise, no interesse público, na medida em que uma prestação de serviços eficaz, imparcial e de qualidade só se consegue através de um quadro de pessoal eficiente. Para se obter isto, além de concurso público, avaliação periódica de desempenho e um certo tempo de exercício, fundamental na aquisição de experiência, o Estado necessita oferecer algumas vantagens, como, por exemplo, a estabilidade, para atrair as pessoas mais capacitadas para o serviço público.
\end{abstract}

Assim, a estabilidade, além de servir de instrumento para eficiência, serve também para atrair bons profissionais, capacitados a melhor atender o interesse comum. Nesse sentido, "sobre a ótica da coletividade, a estabilidade traz benefícios a esta, pois, na medida em que o servidor público exerce seu trabalho com mais garantias, tem mais tranquilidade para prestar um serviço de melhor qualidade à comunidade" (COUTINHO, 2003, p. 75).

Outro fundamento, que tem especial importância, é o fato de a estabilidade servir como garantia à continuidade. $\mathrm{O}$ instituto teve suas origens nos Estado Unidos com o intuito de dar fim as alterações completas realizadas no quadro funcional ocorridas quando havia troca no poder, o que prejudicava a continuidade do serviço público (DINIZ, 1998 apud LEHMEN; BITENCOURT, 2019).

Souza (2002, p. 79) diz que "a estabilidade tem como preceito básico impedir a descontinuidade administrativa". Lehmen e Bitencourt (2019) complementam que, a despeito de ter origem americana, a estabilidade pode ser aplicada ao Brasil como meio para assegurar que não haja interrupção na continuidade dos serviços. 


\section{CONSIDERAÇÕES FINAIS}

Ao longo do tempo, a estabilidade do servidor público ocupante de cargo em caráter efetivo tem sido alvo de grandes críticas, sendo, por muitos, apontada como causa da ineficiência administrativa e da consequente má qualidade dos serviços prestados pelo Estado. Isso, no entanto, conforme pode-se verificar, mostra-se equivocado.

No tocante à classificação dos agentes públicos, restou demonstrado que, apesar de constituírem grande parte das pessoas que prestam serviços em nome do Estado, os servidores públicos ocupantes de cargos em caráter efetivo não são os únicos responsáveis pela prestação dos mesmos. Os agentes políticos, terceiros em colaboração, empregados públicos, agentes temporários e servidores ocupantes de cargo em comissão são também responsáveis pelo cumprimento dos princípios básicos tanto da Administração Pública, quanto do serviço público. Disso, evidenciase a incoerência em aplicar toda a responsabilidade pelas mazelas do Estado a uma só classe.

Ademais, diante do que foi analisado, é imperioso que o Estado ofereça alguma segurança a esses servidores para que eles possam atuar conforme seus regramentos legais sem sucumbirem a pressões exercidas, em especial, pelos agentes políticos e servidores públicos ocupantes de cargo em comissão. A estabilidade, desse modo, além de ser uma garantia ao servidor, constitui uma garantia à sociedade, para que as pessoas possam ter à sua disposição os serviços de que necessitam.

Da mesma forma, pode-se observar que, principalmente após a Emenda Constitucional $n^{\circ} 19$ de 1998, a estabilidade não possui caráter absoluto. Portanto, a Administração Pública, se usar bem dos mecanismos postos à sua disposição, notadamente a avaliação de desempenho, pode garantir que somente aqueles mais bem preparados possam permanecer em seu cargo. Ocorre que, conforme pode-se verificar, a lei complementar necessária para regulamentar o art. $41, \S 1^{\circ}$, III, da Constituição, que prevê a hipótese de perda da estabilidade por procedimento de avaliação periódica de desempenho, até hoje não foi promulgada.

Assim, pode-se concluir que a estabilidade é vantajosa também à sociedade, sendo que, a Constituição elenca os mecanismos necessários para que servidores 
públicos ineficientes não permaneçam no serviço público. Desse modo, não podem os servidores públicos ocupantes de cargo efetivo serem responsabilizados pela ingerência do Estado em aplicar tais dispositivos de controle. Destaca-se, por fim, que os fundamentos do próprio instituto se voltam no sentido de que este surgiu para garantir a eficiência, efetividade, qualidade e continuidade dos serviços públicos.

\section{REFERÊNCIAS}

ALMEIDA, Fabricio Bolzan de. Manual de direito administrativo. 3. ed. São Paulo: Saraiva Educação, 2019.

ARAÚJO, Edmir Netto de. Curso de direito administrativo. 8. ed. São Paulo: Sarava Educação, 2018.

BRASIL. [Constituição (1988)]. Constituição da República Federativa do Brasil de 1988. Disponível em: http://www.plananlto.gov.br/ccivil_03/constituicao/ constituicao.htm. Acesso em: 23 mar. 2020.

. [Decreto n. 1.171 (1994)]. Decreto n. 1.171 de 22 de junho de 1994. Aprova o Código de Ética Profissional do Servidor Público Civil do Poder Executivo Federal. Disponível em: <https://www.planalto.gov.br/ccivil_03/decreto/d1171.htm>. Acesso em: 30 mar. 2020.

. [Lei. n. 8.987 (1995)]. Lei n. 8.987 de 13 de fevereiro de 1995. Dispõe sobre o regime de concessão e permissão da prestação de serviços públicos previsto no art. 175 da Constituição Federal, e dá outras providências. Disponível em: http://www.planalto.gov.br/ccivil_03/LEIS/L8987cons.htm. Acesso em: 09 abr. 2020.

. Supremo Tribunal Federal. Súmula nº 21 de 13 de dezembro de 1963. Disponível em: <http://www.stf.jus.br/portal/jurisprudencia/listarJurisprudencia.asp? s1=21.NUME.\%20NAO\%20S.FLSV.\&base=baseSumulas>. Acesso em: 29 abr. 2020.

CARVALHO FILHO, José dos Santos. Manual de direito administrativo. 32. ed. São Paulo: Atlas, 2018.

COUTINHO, Ana Luísa Celino. Servidor público: reforma administrativa, estabilidade, empregado público, direito adquirido. 1. ed. Curitiba: Juruá, 2003.

COUTO, Reinaldo. Curso de direito administrativo. 3. ed. São Paulo: Saraiva Educação, 2019. 
DI PIETRO, Maria Sylvia Zanella. Direito administrativo. 32. ed. Rio de Janeiro: Forense, 2019. E-book.

GASPARINI, Diogenes. Direito administrativo. 17. ed. São Paulo: Saraiva, 2012.

LEHMEN, João Felipe; BITTENCOURT, Caroline Muller. A estabilidade do servidor público como condição a manutenção da qualidade do ensino básico: reflexões necessárias a partir da prestação dos serviços pelo terceiro setor. Revista de Estudos e Pesquisas Avançadas do Terceiro Setor. Brasília, v. 6, n. 1, p 277-298, jan-jul, 2019. DOI: http://dx.doi.org/10.31501/repats.v6i1\%20JAN/JUL.10483. Disponível em: https://portalrevistas.ucb.br/index.php/REPATS/article/view/277. Acesso em: 29 abr. 2020.

MATIAS-PEREIRA, José. Administração pública: foco nas instituições e ações governamentais. 5.ed. São Paulo: Atlas, 2018. E-book.

MARINELA, Fernanda. Direito administrativo. 12. ed. São Paulo: Saraiva Educação, 2018.

MICHAELIS. Dicionário brasileiro da língua portuguesa. Disponível em: https://michaelis.uol.com.br/moderno-portugues/busca/portuguesbrasileiro/qualidade/. Acesso em: 16 abr. 2020.

MEDAUAR, Odete. Direito administrativo moderno. 21. ed. Belo Horizonte: Fórum, 2018.

MEIRELLES, Hely Lopes. Direito administrativo brasileiro. 42. ed. São Paulo: Malheiros, 2016.

MELLO, Celso Antônio Bandeira de. Curso de direito administrativo. 32. ed. São Paulo: Malheiros, 2014.

MORAES, Alexandre de. Direito constitucional. 35. ed. São Paulo: Atlas, 2019. Ebook.

NOHARA, Irene Patrícia. Direito administrativo. 9. ed. São Paulo: Atlas, 2019. Ebook.

OLIVEIRA, Rafael Carvalho Rezende. Princípios do direito administrativo. 2. ed. Rio de Janeiro: Forense, 2013.

Curso de direito administrativo. 7. ed. Rio de Janeiro: Forense; São

Paulo: Método, 2019. E-book. 
SOUZA, Teresa Cristina Padilha de. Mérito, estabilidade e desempenho: influência sobre o comportamento do servidor público. 2002. Tese (Mestrado em Gestão Empresarial) - Escola Brasileira de Administração Pública e de Empresas, Fundação Getúlio Vargas, Rio de Janeiro, 2002. Disponível em:<https://bibliotecadigital.fgv.br/ dspace/handle/10438/3759>. Acesso em: 23 abr. 2020.

Artigo recebido em: $21 / 05 / 2020$

Artigo aceito em: 20/08/2020

Artigo publicado em: 15/09/2020 